JURNALYOGA DAN KESEHATAN

JURUSAN YOGA KESEHATAN

FAKULTAS BRAHMA WIDYA

IHDN DENPASAR
Vol. 3 No. 2 September 2020

ISSN : 2621-0185 (Cetak)

ISSN : 2722-9440 (Online)

http://ejournal.ihdn.ac.id/index.php/jyk

\title{
Implikasi Yoga Marga Terhadap Kesehatan Rohani
}

\author{
Yunitha Asri Diantary Ni Made ${ }^{\mathbf{1}}$, I Made Hartaka \\ Sekolah Tinggi Agama Hindu Negeri Mpu Kuturan Singaraja \\ Email: yunitha27@gmail.com ${ }^{1}$, made.hartaka@gmal.com ${ }^{2}$
}

Diterima tanggal 31 Juli 2020, diseleksi tanggal 16 Agustus 2020, dan disetujui tanggal 27 Agustus 2020

\section{ABSTRACT}

Hindus have a noble purpose in life namely moksartham jagadhita ya ca iti dharma or attain jagadhita (physical well-being) and moksa (inner peace). This goal can be achieved by a variety of paths known as catur marga or catur yoga. Catur marga or catur yoga is a method or way that can be done to get closer between humans and God. The catur yoga marga are bhakti yoga, karma yoga, jnana yoga, and raja yoga. Each individual can take the path that he wants to pursue to reach God. This path is carried out with a sincere heart and in accordance with the conditions of each Hindu. Through this yoga path, Hindus can actualize their lives in accordance with their respective obligations. Self-control through mind control as a whole through the practice of meditation can be a medium in achieving this life goal. Control of the senses and the human mind is key in managing the mental and spiritual health of mankind. In yoga this self-control is very important and important to apply, so it is obligatory to do meditation in this life as a way to achieve spiritual health that is directly related to physical health. A healthy mind will mean creating a healthy body.

Keywords: implications; yoga marga; spiritual health

\section{ABSTRAK}

Umat hindu memiliki tujuan hidup yang mulia yaitu moksartham jagadhita ya ca iti dharma atau mencapai jagadhita (kesejahteraan jasmani) dan moksa (ketentraman batin). Tujuan ini dapat dicapai dengan berbagai macam jalan yang dikenal dengan catur marga atau catur yoga. Catur marga atau catur yoga ini merupakan metode atau cara yang dapat dilakukan untuk mendekatkan diri antara manusia dan Tuhan. Adapun bagian catur marga yoga ini adalah bhakti yoga, karma yoga, jnana yoga, dan raja yoga. Setiap individu dapat menempuh jalan yang ingin dia tekuni untuk mencapai Tuhan. Jalan ini dilaksanakan dengan hati yang tulus dan sesuai dengan kondisi masing-masing umat Hindu. Melalui jalan yoga ini umat hindu dapat mengaktualisasikan kehidupannya secara baik sesuai dengan kewajibannya masing-masing. Pengendalian diri melalui pengendalian pikiran secara utuh melalui praktik meditasi dapat menjadi media dalam mencapai tujuan hidup ini. Pengendalian indria dan pikiran manusia merupakan kunci dalam mengelola kesehatan mental spiritual umat manusia. Dalam yoga pengendalian diri ini sangat utama dan penting untuk diterapkan, sehingga wajib melakukan meditasi dalam kehidupan ini sebagai cara untuk mencapai kesehatan rohani yang berhubungan langsung dengan kesehatan jasmani. Sebuah pikiran yang sehat akan berarti mewujudkan tubuh yang sehat pula.

Kata kunci: implikasi; yoga marga; kesehatan rohani 


\section{PENDAHULUAN}

Manusia adalah makhluk utama yang memiliki kualifikasi paling sempurna dibandingkan dengan makhluk hidup lainnya. Secara fundamental manusia merupakan makhluk rational karena berpikir dengan akal (budi) pikirannya. Akal pikirannya ini merupakan dasar penting dalam pengembangan wiweka, yakni kemampuan akal pikiran rational dalam mempertimbangkan sesuatu secara arif bijaksana. Oleh karena itu secara konseptual manusia dalam pandangan Hindu adalah manusia yang mampu mengembangkan dan mengedepankan daya piker dan pikiran rational (manah) untuk menjadikan dirinya sendiri sebagai manusia (Swayambu Manu) dalam tatanan hidup dan kehidupan ini. Eksistensi manusia dalam padangan agama Hindu yaitu makhluk yang memiliki badan dan jiwa, dimana badan dan jiwa ini memiliki hakikat yang sama pentingnya dan memiliki hubungan antara satu dengan lainnya. Badan tanpa jiwa tidak akan berguna, begitu pula jiwa tanpa badan tidak dapat berbuat apa-apa.

Tujuan hidup manusia juga dijelaskan dalam ajaran catur purusartha yaitu dharma, artha, kama, dan moksa. Moksa adalah tujuan hidup tertinggi dan mulia bagi umat Hindu. Ia merupakan "sommum bonum" dalam tata filsafat Hindu yang berhasil tidaknya akan tergandung pada pengamalan dharmanya. Disinilah wajib umat Hindu merasa bersyukur menjadi manusia yang merupakan penjelmaan atma yang paling sulit sekaligus yang paling penting, karena hal tersebut merupakan sebuah perjuangan dari semasa hidup terdahulu yang ditandai dengan pergulatan antara kebajikan dan kebatilan, disamping kenyataannya bahwa perjalanan menuju arah status keberadaab tertinggi yang disebut moksa, baru bias didapat dimulai dari titik eksistensi sebagai manusia. Masyarakat cenderung memiliki sikap individualis yang menganggap bahwa mereka mampu melakukan segala hal tanpa bantuan orang lain dan tidak ingin terlibat dalam urusan orang lain (Hartaka, dkk., 2020: 18).

Dalam ajaran agama hindu terdapat empat cara untuk mencapai moksa, yakni dengan melaksanakan salah satu ajaran dari catur marga atau catur yoga yang terdiri dari bhakti marga (bhakti yoga), jnana marga (jnana yoga), karma marga (karma yoga), dan raja marga (raja yoga). Dalam setiap pelaksanaannya diperlukan sebuah pengendalian diri dari setiap umat manusia, dan sebuah kesadaran yang merupakan sumber pemikiran dan tindakannya. Menurut Yogi Ramacharaka, dalam susunan fisik, mental dan rohani umat terdapat sifat yang tertinggi dan terendah. Dalam tulang-tulangnya terdapat kehidupan yang bersifat mineral. Badan dan darahnya benar-benar mengandung bahan mineral. Manusia juga memiliki sifat mental. Disamping itu ada daya kemauan yang merupakan daya "aku", karena itu umat manusia harus dapat menguasai dan mengendalikan "miliknya". Manusia harus menyadari dirinya secara benar, dan dapat membedakan mana yang merupakan "aku" dan mana yang merupakan "milik aku" serta mana 
yang "bukan aku" sebuah pengendalian diri dan kesadaran ini yang akan mengarahkan manusia mecapai kesehatan rohaninya atau sehat dari keegosian kehidupan.

Manusia mesti meningkatkan kesadaran guna mendekatkan diri kepada Ida Sang Hyang Widhi Wasa yang berlandaskan susastra suci. Metode yang banyak diungkapkan dalam susastra suci ialah dengan melakukan jalan yoga (yoga marga). Era global seperti saat ini sangatlah diperlukan segala sesuatu yang mentralisir kehidupan yang lebih cendrung mengarah ke hal yang negatif, perlu adanya sebuah pemulihan kesadaran. Kemajuan teknologi dan segala hal yang mempermudah kehidupan yang disatu sisi memudahkan akses, namun sebaliknya menyebakan kehidupan semakin hedonis. Ajaran yoga marga dapat dijadikan pijakan dalam kehidupan keseharian.

\section{PEMBAHASAN}

\subsection{Ajaran Yoga Marga}

Secara original, ajaran catur marga merupakan suatu konsep ajaran yang memuat empat jalan utama dalam menuju Tuhan (Ida Sang Hyang Widhi Wasa). Adapun keempat jalan tersebut adalah; 1) Bhakti Marga, 2) Karma Marga, 3) Jnana Marga, dan 4) Raja Marga (Adiputra, 2003:23-24). Keempat jalan tersebut merupakan metode atau cara yang dapat dilakukan untuk mendekatkan diri antara manusia dan Tuhan, ataupun mencapai penyatuan antara Atman dengan Ida Sang Hyang Widhi Wasa sebagai Paramaatman. Ajaran marga yoga jika dikaitkan dengan pengembangan kecerdasan manusia dapat pula diuraikan sebagai berikut:

1) Karmayoga dan Rajayoga sebagai wahana pengembangan kinestetik.

2) Jñānayoga sebagai wahana pengembangan kecerdasan intelektual (IQ)

3) Bhaktiyoga sebagai wahana pengembangan emosional (EQ), dan

4) Vibhutiyoga sebagai pengembangan (SQ).

Pengembangan kesadaran tersebut di atas memiliki kompleksitas yang tinggi, terdapat hubungan saling melengkapi antara yang satu dengan yang lain, dan hal ini tergantung pula dari karakter dan kecenderungan seseorang, di samping karena faktor pendidikan dan lingkungan sosial, budaya, dan alamnya (Hartaka, 2019: 162).

Menurut Sivananda (2003:133) empat jalan spiritual yang utama untuk mewujudkan Tuhan adalah Karma Yoga, Bhakti Yoga, Raja Yoga dan Jnana Yoga. Karma Yoga cocok bagi orang yang bertempramen aktif, Bhakti Yoga bagi orang yang bertempramen bhakti, Raja Yoga bagi orang yang bertempramen mistis, dan Jnana Yoga bagi orang yang bertempramen rasional dan philsofis. Berikut penjelasan lebih mendetail mengenai pembagian dari catur marga atau catur yoga ini. 


\section{a. Bhakti Marga atau Bhakti Yoga}

Menurut Sura, (1991:24) Bhakti Yoga dapat dilakukan dengan cara shravanam atau mendengarkan pujian tentang kemuliaan Tuhan, manana atau sembahyang dengan teratur, dan kartana atau dengan menyanyikan kidung tentang kemuliaan Tuhan. Untuk melaksanakan Bhakti Marga atau Bahkti Yoga, umat Hindu tidak memerlukan apapun, kecuali kesucian dan hasrat bhakti yang murni untuk menghubungkan diri dengan Ida Sang Hyang Widhi Wasa.

b. Karma marga atau Karma Yoga

Karma yoga adalah jalan kegiatan yaitu jalan pelayanan tanpa pamrih, yang membawa pencapaian Tuhan melalui kerja tanpa pamrih. Motto seorang karma-yogin adalah "kewajiban demi untuk kewajiban itu sendiri”. Bagi seorang karma yogin, kerja adalah pemujaan, sehingga setiap pekerjaan dialihkan menjadi suatu pemujaan kepada Tuhan. Seorang karma yogin tak terikat oleh karma, karena ia mempersembahkan buah perbuatannya kepada Tuhan. Yogah karmasu kausalam, yoga adalah keterampilan dalam kegiatan (Sivananda, 2003:134).

c. Jnana Marga atau Jnana Yoga

Jnana yoga adalah jalan pengetahuan. Moksa dicapai melalui pengetahuan tentang Brahman. Pelepasan dicapai melalui realisasi identitas dari roh pribadi dengan roh tertinggi atau Brahman. Pengetahuan tentang Brahman atau Brahman Jnana membuka selubung ini dan membuat Jiwa bersandar pada sat cit ananda swarupa (sifat utamanya sebagai keberadaan, kesadaran, kebahagian mutlak) dirinya. Ada tujuh tahapan dari jnana atau pengetahuan, yaitu; aspirasi pada kebenaran (subhecha), pencarian filosofi (wicarana), penghalusan pikiran (tanumanasi), pencapaian sinar (sattwapatti), pemisahan batin (asam-sakti), penglihatan spiritual (padartha-bhawana) dan kebebasan tertinggi (turiya) (Sivananda, 2003:139).

d. Raja Marga atau Raja Yoga

Raja yoga adalah jalan yang membawa kepenyatuan dengan Tuhan, melalui pengekangan diri dan pengendalian pikiran. Raja yoga mengajarkan bagaimana mengendalikan indriya-indriya dan wrtti mental atau gejolak pikiran yang muncul dari pikiran, bagaimana mengembangkan konsentrasi dan bagaimana bergaul dengan Tuhan. Dalam hatha yoga terdapat disiplin fisik, sedangkan dalam raja yoga terdapat disiplin pikiran (Sivananda, 2003:136). Pikiran sangatlah berperan dalam menentukan arah dari perjalanan kehidupan manusia dan pikiran sangatlah sulit untuk dikendalikan.

\subsection{Yoga dalam Susastra Hindu}

Kata yoga secara etimologi berasal dari bahasa sanskerta yaitu dari akar kata yuj yang berarti menghubungkan. Dalam pengertian lebih luas, yoga berarti hubungan antara jiwa dengan 
roh universal yang disebut Tuhan (Brahman). Dalam pengertian ini yoga merupakan suatu cara untuk mencapai suatu kesempurnaan yaitu Dharma dan Moksa dengan memusatkan pikiran kepada Ida Sang Hyang Widhi Wasa, sehingga secara perlahan-lahan akan dapat membebaskan diri dari ikatan-ikatan keduniawian. Patanjali mendefinisikan yoga sebagai yogascitta vrthi nirodayogascitta vrthi niroda yang berarti yoga adalah pengendalian gelombang-gelombang pikiran.

Menurut Tristaningrat (2018: 146) yoga pada dasarnya adalah sebuah cara atau jalan hidup, bukan sesuatu yang keluar dari kehidupan, bukan pula menjauhkan diri dari aktifitas, melainkan merupakan performa yang efesien dengan semangat hidup yang benar. Pembentukan sikap diawali dengan disiplin diri termuat dalam Rgveda XIX.83.1

\section{Ataptatanur na tadamo astnute}

Terjemahan:

Orang yang tanpa menjalankan tapa (pengekangan diri) yang keras, tidak dapat menyadari Tuhan Yang Maha Esa.

Setelah pancaindria terkendali dan pikiran sudah terbebas dari pengaruhnya, maka secara otomatis pengaruh nafsu juga akan musnah dan terkendali. Untuk mencapai keadaan seperti ini, maka kita harus sering melakukan introspeksi kedalam diri, sering melakukan perenungan atau mengheningkan pikiran dan hati, sehingga antara pikiran dan hati selalu terjadi dialog tentang kebenaran yang hakiki yaitu Tuhan Yang Mahabenar.

Te Dhyana-yoganugata apasyan devatma-saktim sva-gunair nigudham, yah karanani nikhilani tani kalatma-yuktany adhitisthaty ekah.

Terjemahan:

(Svetasvatara Upanisad I.3)

Mereka yang tiada hentinya (berbakti dengan) semadi melihat kekuatan diri Tuhan yang tersembunyi dalam sifatnya sendiri. Dialah penguasa semuanya dari semua sebab-sebab dari waktu sampai kepada jiwa

Yoga tidak hanya bermanfaat bagi kesehatan tubuh jasmani melainkan juga kesehatan rohani. Melalui yoga ketenangan pikiran dapat digapai, karena ketenangan pikiran membawa pengaruh besar pada setiap akivitas yang dilakukan, maka dari itu pikiran yang seimbang membantu setiap orang untuk meningkatkan spiritualnya atau kesucian dirinya. Dalam lontar Bhuwanakosa II.19 mengungkapkan,” Diusahakan untuk mengosok kayu itu, lalu keluarlah api, di dunia ini demikianlah halnya Sang Hyang Iswara akan dapat dibayangkan dengan jalan mendalami Yoga”. Ibarat tubuh adalah sebuah kesadaran dan pikiran sebagai pengemudinya. Saat "mengemudikan" tubuh, pikiran terpengaruh oleh tiga hal, yakni emosi, akal, dan aksi. Agar 
tubuh tetap dapat berorientasi dengan baik, ketiga hal yang mempengaruhi pikiran ini harus selalu dalam keadaan seimbang.

Wraspati Tattwa 52 yang juga menjelaskan menjelaskan terdapat tiga prilaku untuk mencapai kesempurnaan, yaitu; 1) Jnanabhyudreka, mengetahui sumber-sumber ajaran atau tattwa, 2) Indrayogamarga, tidak tenggelam dalam kesukaan hawa nafsu, dan 3) Trsnadosaksaya, menghilangkan pahala dari perbuatan baik dan buruk. Seseorang yang telah memiliki pengetahuan yang tinggi, akan memilih jalan yoga yang paling tinggi yaitu dengan jalan mistik atau jalan raja yoga. Bahkan dalam lontar Bhuwana Sang Ksepa 53 mengungkapkan "Tan dadi hana yan tan hana Omkara yan tan hana aku. Hana aku hana Omkara; Hana Omkara hana aku. Matangnyan kari aku magawe yoga", yang terjemahanya: tidak ada "ada" bila tidak ada Omkara, bila tidak ada Aku. Ada Aku, ada Omkara. Ada Omkara ada Aku. Karena itu Aku-pun terus melaksanakan yoga. ini menandakan bahwa yoga juga memiliki peran central dari keberadaan alam semesta. Maka, untuk dapat mencari kebenaran lebih jauh tentang keberadaan Tuhan Yang Maha Rahasia diperlukan ilmu pengetahuan (Jnana) guna menguak tabir misteri dari Sang Maha Misteri. Karma serta Bhakti Marga sebagai upaya memperkuat jasmani dan Raja Marga sebagai wahana mengendalikan pikiran.

\subsection{Pengelolaan Mental Spiritual melalui Yoga}

Yoga membantu manusia dalam mengendalikan diri, mengendalikan perbuatan, ucapan dan membersihkan badan dari pranayama. Yoga juga dapat dikatan sebagai ilmu tentang kehidupan, karena seluruh aspek kehidupan dapat dikaitkan dengannya. Walaupun telah berumur ribuan tahun, yoga dirasakan tetap sesuai dengan yang dipraktekkan oleh masyarakat modern saat ini. Dengan memperaktekkan yoga secara teratur seseorang berlatih untuk meredam emosinya. Emosi yang dimaksud adalah marah-marah, sedih, takut, keraguan, jadi semuanya dilepaskan secara positif dan tidak terlalu lemah dalam menghadapi berbagai permasalahan yang tidak bias dihindari dalam kehidupan sehari-hari (Darmayasa, 2013:7)

Keyakinan bahwa setiap manusia memiliki nilai-nilai positif dalam pikirannya maka hendaknya hal tersebut tetap dipertahankan. Ketika lebih dikaji secara mendalam terdapat keterikatan yang kuat antara bagiamana kewajiban seorang manusia dalam bermasyarakat dengan bagaimana menjalani hidup sesuai kaidah-kaidah keagamaan (Hartaka, 2020: 38). dalam Kitab Niti Sataka Sloka 31 menyebutkan.

Trsnam chindhi bhaja ksamam jahi madam pape ratim markrthah

Satyam bruhyanuyahi sadhupadavim sevasva vidvajjanam

Manyanmanaya vidvisoapyanunaya pracchadaya svan gunan

Kirtim palaya dukhita kuru dayametatsatam laksanam 
Terjemahan:

Sifat-sifat baik yang sudah ada dalam diri manusia dapat dikembangkan dengan membuang keserakahan, bersedia memaafkan, membuang sifat sombong, tidak berbuat dosa, selalu mengucapkan kebenaran, mengikuti orang bijaksana, menghargai orang yang patut dihormati, kasihan kepada musuh dan kasihan kepada orang yang sedang dalam kesulitan

Menurut Somvir (2009:14) diam adalah emas adalah konsep yoga. Semakin pikiran manusia tidak stabil, sempit, dan penuh dengan kama (keinginan), krodha (kemarahan), lobha (keserakahan), moha (keterikatan), matsara (iri hati), dan ahamkara (ego). Dalam kondisi tersebut manusia akan mengekspresikan dengan berbagai cara, bahkan ia akan berbicara yang tidak perlu, pelan-pelan akan memiliki kebiasaan banyak bicara. Semakin banyak bicara manusia akan semakin stress, terutama mereka yang tidak memiliki dasar spiritualitas. Hal ini karena disebutkan manusia melupakan yoga, pikiran tidak terkendali maka akan berpikir yang tidak perlu.

Terdapat dua pandangan yang membahas tentang konsep latihan yoga. Pandangan yoga klasik fokus di aktivitas yang mengembangkan insight untuk memahami kebenaran mengenai diri manusia sedang pandangan hatha yoga fokus di aktivitas yang mengembangkan kesehatan fisik dan psikologis. Guna mendapat hasil yang maksimal secara fisik, psikilogis dan spiritual, orang yang melakukan yoga dianjurkan untuk berlatih dengan dua konsep tersebut (Stiles, 2002). Latihan yoga dapat meningkatkan kesadaran seseorang terhadap tubuhnya atau sering disebut proses embodiment (Impett, Daubainmer, Hirschman, 2006). Saat berlatih yoga seseorang dilatih untuk menyadari sensasi tubuh serta mengenal tubuhnya sehingga memunculkan penghargaan terhadap fungsi tubuh, proses embodiment memudahkan seseorang untuk mengenal sensasi tubuh saat muncul pikiran dan perasaan tertentu seperti saat merasa cemas, lelah, marah dll. Terdapat filosofi yoga tentang penguasaan pikiran yang menyebutkan istilah "aku bukanlah pikiranku, aku bukanlah perasaanku (Sindhu, 2007). Istilah tersebut sesuai dengan konsep embodiment agar memudahkan seseorang untuk mengenal tubuhnya, pikiran dan perasaannya. Seseorang dilatih untuk hadir di saat sekarang memusatkan perhatian terhadap tubuh. Pemusatan perhatian terhadap tubuh bertujuan mengembangkan kemampuan seseorang untuk berempati dan memberi penghargaan pada apapun yang terjadi dalam tubuh (Weiss dalam Kinasih, 2010). Penghargaan terhadap diri sendiri juga memudahkan seseorang untuk menghargai orang lain dan lingkungan sekitar. Individu menjadi lebih mudah bersyukur dan menerima setiap kondisi. 


\subsection{Dampak Meditasi Bagi Peningkatan Kesehatan Rohani}

Kata rohani dalam Kamus Besar Bahasa Indonesia mempunyai arti roh dan juga berkaitan dengan yang tidak berbadan jasmaniah. Sedangkan persamaan kata rohani adalah kejiwaan. Keterikatan jiwa pada maya menyebakan ketidakseimbangan dalam pemikiran dan sulit mendapatkan kebahagiaan diri. Kesehatan rohani dalam Hindu dapat diartikan sebagai kondisi pikiran yang terkendali, sehingga dapat menunjukan sifat atau perilaku sattwika. Dalam Wrhaspati Tattwa 17 disebutkan," Kejujuran, kebebasan, kelembutan, keagungan, ketangkasan, kehalusan, dan keindahan adalah sifat-sifat dari pemikiran sattvika... ”. Pengendalian indria dan pikiran manusia merupakan kunci dalam mengelola kesehatan mental spiritual umat manusia. Sehingga dalam yoga pengendalian diri ini sangat utama dan penting untuk diterapkan.

Problema terbesar yang dihadapi sesungguhnya bukanlah dunia luar, tetapi kemampuan diri kita untuk mengendalikan panca indriya guna mencapai keseimbangan jiwa. Panca indriya yang tidak terkendali menyeret kita ke lembah penderitaan atau Samsara (Hartaka, 2020: 41). Melalui meditasi manusia dapat melatih disiplin diri, mengendalikan hawa nafsu, seperti dikemukan dalam Bhagavadgita VI.27, sebagai berikut:

\section{Prasanta manasam hy enam yoginam sukham uttamam, upa iti Santarajasam brahmabhutanam akalmâ̂am}

Terjemahan:

Karena kebahagiaan tertinggi datang pada yogin yang pikirannya tenang, nafsunya tak bergolak, keadaanya bersih dan bersatu dengan Tuhan (Mantra, 2019: 147).

Menurut Sivananda (2005:25) pikiran secara amat dekat dengan tubuh. Pikiran bereaksi terhadap tubuh dan tubuh bereaksi terhadap pikiran. Pikiran memiliki pengaruh terhadap seluruh tubuh. Sebuah pikiran yang sehat akan berarti mewujudkan tubuh yang sehat pula. Sedangkan penyakit pada pikiran sudah tentu akan menjadi penyakit bagi tubuh. Meditasi sesungguhnya sudah diperaktikkan leluhur Nusantara kuno sebagai metode mistik bagi mereka yang ingin menemukan pembebasan diri dan kesejatian hidup. Meditasi telah menjadi pokok kajian para mistikus Nusantara sejak lama. Mereka begitu tekun melakoni meditasi hingga merengkuh kedalam dirinya dan mencapai kebebasan. Leluhur Nusantara bahkan menjadikan meditasi sebagai kebutuhan dan asupan bagi jiwa untuk menemukan hakikat realitas kehidupan (Sandika,2019:183). Patanjali menulis sutra dan memberikan pejelasan bahwa, setelah manusia membersihkan badan maupun pikiran perlu melakukan perenungan kepada Tuhan. dijelaskan “dhayanam nirvishayam” yang berarti ketika pikiran mencapai nirvishaya (terbebas dari segala obyek indera, dan kenikmatannya) maka itulah yang dinamakan meditasi. 
Menurut Jendra dalam Darmayasa (2013:102) meditasi berasal dari bahasa inggris meditation. Kata ini termasuk kata benda dalam bahasa inggris, sedangkan kata kerjanya adalah meditate yang artinya merenung, tafakur. Kata dalam bahasa inggris ini kemudian diucap dalambahasa Indonesia menjadi meditasi, karena disesuaikan dengan kaidan bahasa Indonesia. Sedangkan dalam bahasa Sansekerta padanan kata meditasi ini adalah dhyana yakni pemusatan perhatian yang terus menerus kepada suatu objek, sehingga seseorang yang melakukan meditasi bias mencapai perenungan diri yang paling dalam. Meditasi (dhyana) merupakan proses lebih lanjut dari dharana yang berarti konsentrasi atau pemusatan perhatian kepada sesuatu yang dijadikan objek meditasi.

Karena ketenangan yang ditimbulkannya, meditasi ini sangat baik bagi kesehatan tubuh, untuk relaksasi, memungkinkan tidur yang nyenyak, memberikan efisiensi pada semua pekerjaan yang kita hadapi. Saat sedang gelisah dan kita mengamati napas kita untuk beberapa saat, maka segera akan terasa ketenteraman dan kedamaian. Meditasi pada napas membuat kita tenang dan damai (Wijoyo, 2020) Dalam Penelitian Herbert Benson, M.D., Harvard Medical School, manfaat meditasi yaitu meningkatkan asupan oksigen, menstabilkan detak jantung, pernapasan, dan tekanan darah, serta meningkatkan intensitas gelombang alfa, teta, dan delta yang merupakan fisiologis saat respon stress terjadi. Selain itu meditasi juga memberikan dampak ketenangan emosi dan pikiran, yang mana saat meditasi dilakukan bekerjanya kelenjar pineal, yaitu kelenjar yang terletak di tengah-tengah otak.

Lebih lanjut Wimalatissa menyatakan bahwa meditasi sangat bermanfat untuk kesehatan fisik dan mental serta mempunyai kemampuan untuk membalik efek buruk dari gangguangangguan fisik dan psikis: According to findings of modern psychology, chronnic stress plays a major role in many psychological disorders as well as physical diseases. Such psychological and physical disorders such as depression, anxiety, heart diseases, sleeping problems, digestive problems, memory problems, and skin conditions are caused by stress. As soon as someone is stressed, the brain send out a signal through the nervous system to all part of the body to get ready and respond by releasing sress hormone, including adrenaline and cortisol. Long term exposure to stress can lead to serious health problem. Chronic stress disrups every system in the body. It can raise blood pressure, suppress the immune system, increase the risk of heart attack and stroke, contribute to infertility and speed up the aging process. The regular practice of meditation apparently helps to avert mental stress. Yang artinya "Menurut temuan psikologi modern, stres kronis memainkan peran utama dalam banyak gangguan psikologis serta penyakit fisik. Gangguan psikologis dan fisik seperti depresi, kegelisahan, penyakit jantung, masalah tidur, masalah pencernaan, masalah ingatan, dan kondisi kulit disebabkan oleh stres. Setelah 160 | YOGA DAN KESEHATAN Vol. 3 No. 2, September 2020 
seseorang stres, otak mengirimkan sinyal melalui sistem saraf ke seluruh bagian tubuh untuk bersiap-siap dan merespons dengan melepaskan hormon stres, termasuk adrenalin dan kortisol. Paparan stres jangka panjang dapat menyebabkan masalah kesehatan yang serius. Stres kronis mengganggu setiap sistem dalam tubuh. Ini dapat meningkatkan tekanan darah, menekan sistem kekebalan tubuh, meningkatkan risiko serangan jantung dan stroke, berkontribusi pada infertilitas dan mempercepat proses penuaan. Latihan meditasi yang teratur tampaknya membantu mencegah tekanan mental.

Meditasi merupakan hal yang penting dilakukan bagi setiap individu, karena memiliki manfaat yang luar biasa dalam menjalankan kehidupan. Kesehatan rohani memiliki hubungan erat dengan kesehatan jasmani, layaknya pikiran yang kurang sehat akan membawa dampak buruk pada kesehatan tubuh. Setiap orang memilki obat sendiri dalam penyembuhan penyakit dalam dirinya sendiri. Melalui meditasi setiap orang tidak hanya dapat menghubungkan diri dengan Tuhan juga memberikan dampak kesehatan rohani. Sebagaima sang Buda berkata "jangan bersandar dengan siapapun dan apapun, kau adalah pelita bagi dirimu sendiri. Jadi jalan meditasi adalah jalan kesunyian untuk melihat kedalam diri secara personal, yang dapat menolong kita lepas dari penderitaan adalah diri sendiri, bukan orang lain. Orang lain tidak akan mampu menjadikan kita bahagia sepenuhnya. Meditasi mampu membawa kehidupan ini menjadi harmonis.

\section{PENUTUP}

Yoga Marga merupakan metode atau cara yang dapat dilakukan untuk mendekatkan diri antara manusia dan Tuhan, ataupun mencapai penyatuan antara Atman dengan Ida Sang Hyang Widhi Wasa sebagai Paramaatman. Kemajuan teknologi dan segala hal yang mempermudah kehidupan terkadang mengantarkan seseorang menyimpang dari ajaran dharma. Yoga membantu manusia dalam mengendalikan diri, mengendalikan perbuatan, ucapan dan membersihkan badan dari pranayama. Yoga juga dapat dikatan sebagai ilmu tentang kehidupan, karena seluruh aspek kehidupan dapat dikaitkan dengannya. Masyarakat tertarik untuk mempelajari yoga dengan berbagai latar belakang. Ada yang menginginkan tubuh agar menjadi lebih baik, yang lainnya ingin menghilangkan ketidaknyamanan pada bagian fisik tertentu. Meditasi membawa banyak manfaat yang bersifat lebih dalam kesejahteraan hidup kita sehari-hari secara lahir dan batin.

\section{DAFTAR PUSTAKA}

Adiputra, I Gede Rudia. 2003. Pengetahuan Dasar Agama Hindu. Jakarta: STAH Dharma Nusantara. 
Darmayasa, I Gede Sukra. 2013. Belajar Yoga Asanas Untuk Kesehatan Jasmani dan Rohani.Denpasar: Pustaka Bali Post.

Hartaka, I. M., Ardiyani, L. P. C., \& Suciani, K. (2020). Berbagai Sikap Terhadap Eksistensi Tuhan Pada Era Industri 4.0. Vidya Darśan: Jurnal Mahasiswa Filsafat Hindu, 2(1).

Hartaka, I. M. (2019, March). Building Patriotism Through Spiritual Awareness Hindu Religion Perspective. In Proceeding International Seminar (ICHECY) (Vol. 1, No. 1).

Hartaka, I. M. (2020). Membangun Semangat Kebangsaan Perspektif Etika Hindu. Genta Hredaya, 3(2).

Imppett, E,A. Daunbenmier, J,J \& Hirschman, A,L. (2006). Minding the body: yoga, embodiment, and well- being. Sexuality Research and Social Policy. Journal of NSRC. Vol 3 (4): 39-48

Kinasih, A, S. (2008). Kajian Teoretis dan Pengalaman Proses Kesadaran Manusia terhadap Lingkungan untuk Mengembangkan Keseimbangan Kehidupan "Berdasar Tinjauan Psikologi Transpersonal". Makalah Temu Ilmiah PsychoExpo Fakultas Psikologi Universitas Indonesia. Tidak Diterbitkan

Mantra, I.B.2019. Bhagawadgita Naskah Sanskerta, Alih Bahasa \& Penjelasan. Denpasar: ESBE Buku.

Sandika, I Ketut. 2019. Tantra Ilmu Kuno Nusantara. Banten: Javanica.

Sindhu, P. (2007). Hidup Sehat dan Seimbang dengan Yoga. Bandung: Qanita

Sivananda, Sri Suami. 2003. Intisari Ajaran Hindu. Surabaya: Paramita.

Sivananda, Sri Suami. 2005. Pikiran Misteri dan Penaklukannya. Surabaya: Paramita.

Somvir. 2009. Yoga \& Ayurveda Selalu Sehat dan Awet Muda. Bali-India Foundation

Stiles, M. (2002). Structural Yoga Therapy: Adapting to The Individual. New Delhi: Goodwill Publishing House

Sura, I Gede. 1991. Agama Hindu, Sebuah Pengantar. Denpasar: Kayumas.

Wimalatissa, K., 2014, "Scientific Findings on the Health Benefits of Meditation". A buddhist approach to Healthy Living, Vietnam Buddhist University. 